ORIGINAL ARTICLE

\title{
Diabetes in a high secure hospital
}

\author{
I A MacFarlane, G V Gill, D Finnegan, J Pinkney
}

Postgrad Med J 2004;80:35-37. doi: 10.1136/pgmi.2003.006601

See end of article for authors' affiliations ......................

Correspondence to: Dr lan MacFarlane, Department of Medicine, Clinical Sciences Centre, University Hospital Aintree, Longmoor Lane, Liverpool L9 7AL, UK. ian.macfarlane@ aht.nwest.nhs.uk

Submitted 18 February 2003 Accepted 28 May 2003
Aims: To determine the prevalence of diabetes mellitus and its possible causes and to assess its control in a high secure hospital.

Methods: A cross sectional survey and a prospective cohort study were conducted. The cross sectional survey included 408 patients admitted under the Mental Health Act, and the prospective study included 22 patients with known diabetes followed up for 24 months. The outcome measures evaluated were drug treatment, status of microvascular and macrovascular complications, glycated haemoglobin, and body mass index.

Results: In the cross sectional survey, 35 out of 408 patients $18.6 \%$; $95 \%$ confidence interval $5.9 \%$ to $11.3 \%$ ) had known diabetes, and all of these had type 2 diabetes. Obesity, cigarette smoking, schizophrenia, and antipsychotic drug use were frequent, and weight gain was common after hospital admission. Glycaemic control was variable, and, although a majority of patients were above recommended treatment targets, control remained stable over the follow up period.

Conclusions: Type 2 diabetes was common in this hospital. Both its prevalence and the suboptimal glycaemic control in some patients probably relate to sedentary life, dietary factors, smoking, and perhaps widespread use of antipsychotic drugs. However, regular multidisciplinary input enabled most patients to maintain relatively stable glycaemic control, with good control of blood pressure and lipids, at levels similar to those seen in community and hospital diabetic clinics. Further modification of lifestyle risk factors is probably needed to reduce the prevalence and impact of diabetes in this patient group.
D abetes mellitus is a chronic disease associated with serious long term complications. Diabetes is thought to affect approximately $3 \%$ of the UK population, ${ }^{1}$ but consumes about $9 \%$ of the total national healthcare expenditure. ${ }^{2}$ Type 2 diabetes poses a major public health problem, because of associated morbidity from microvascular and macrovascular disease and early mortality from cardiovascular disease. Once diagnosed, diabetes requires careful surveillance by health professionals trained in diabetes care, in order to achieve optimal metabolic control, to reduce associated cardiovascular risk factors, and to detect and treat complications.

An increased prevalence of impaired glucose tolerance or diabetes in patients with mental disorders was first suggested over 80 years ago. ${ }^{3}{ }^{4}$ Observations in the modern era also have supported an increased prevalence of type 2 diabetes in patients in psychiatric hospitals ${ }^{56}$ and in those receiving medication with antipsychotic drugs (APDs). ${ }^{7}$ Both the long term care environment and APDs may contribute to weight gain and an increased risk of developing diabetes, and in those with existing diabetes these factors may also result in deterioration of glycaemic control. ${ }^{8}$ All of these problems can be exaggerated in secure hospitals where patients may be held for many years.

In view of the rapidly increasing prevalences of obesity and diabetes in the general population, therefore, and the increasing use of new APDs in psychiatry, some of which may have greater diabetogenic potential than older drugs, we investigated the prevalence and clinical characteristics of diabetes mellitus in one of the UK's largest secure hospitals. Most patients in this hospital are admitted for prolonged periods and receive APD medication. We also report our experiences of treating a cohort of diabetic patients in the hospital who were followed for up to two years. There are very few published data on diabetes mellitus in this neglected patient group.

\section{PATIENTS AND METHODS}

The study was conducted at one of three regional high secure hospitals in the UK. The study was approved by the institutional ethics committee. Patients admitted to the hospital are compulsorily detained under the 1983 Mental Health Act as posing grave and immediate danger to others. At any time in the UK, there are approximately 1700 people in the three hospitals. Approximately $70 \%$ of these have significant mental illness (mostly schizophrenia) and 25\% have psychopathic personality disorders. Some have intellectual impairment. The average length of stay in a high secure hospital is eight years, with 20\% remaining for more than 15 years. Over $70 \%$ of patients are male, and $90 \%$ are under the age of 60 years. ${ }^{9}$

\section{Prospective cohort study}

On admission to this secure hospital all patients with a known diagnosis of diabetes are referred to the health centre where they are seen by a visiting general practitioner. Psychiatric nursing and medical staff arrange opportunistic screening for diabetes as indicated by symptoms or risk factors such as family history. New cases of diabetes detected in this way are also referred to the health centre. As well as receiving a medical assessment, patients with diabetes are seen by a dietitian and a chiropodist and undergo eye screening for retinopathy. The general practitioner either manages the patient's diabetes alone or refers individual patients to a visiting consultant diabetologist. From September 1999 to September 2001 details were recorded of all patients referred with diabetes and seen by the diabetologist on at least two occasions. In addition to clinical details,

Abbreviations: APD, antipsychotic drug; BMI, body mass index; $\mathrm{HbAlc}$, glycated haemoglobin; OHA, oral hypoglycaemic agent 
management decisions and medical problems were recorded, and outcomes such as glycaemic control and body weight were measured.

\section{Prevalence study}

Additionally, on one day in September 2001, the clinical characteristics and management details of all patients with diabetes mellitus in the hospital were studied. The point prevalence was estimated from the total hospital population at the time.

For both studies, glycated haemoglobin (HbAlc) was measured by a laboratory high pressure liquid chromatography method, which was aligned to that used in the diabetes control and complications trial. ${ }^{10}$ Body mass index (BMI) was calculated as the patient's weight $(\mathrm{kg})$ divided by the square of their height (m). BMI levels of $20.0-24.9 \mathrm{~kg} / \mathrm{m}^{2}$ were regarded as normal, $25.0-29.9 \mathrm{~kg} / \mathrm{m}^{2}$ as overweight, 30.0 $34.9 \mathrm{~kg} / \mathrm{m}^{2}$ as grade 1 obesity, $35.0-39.9 \mathrm{~kg} / \mathrm{m}^{2}$ as grade 2 obesity, and $>40 \mathrm{~kg} / \mathrm{m}^{2}$ as grade 3 obesity. ${ }^{11}$

\section{RESULTS}

\section{Prospective cohort study}

During the 24 months of the study, serial data were obtained from 22 (four female) patients with diabetes, all of whom had type 2 diabetes. Clinical details are shown in table 1. Out of the 22 patients, 18 had significant mental illness-mostly schizophrenia-and had received or were receiving a variety of APDs and other psychoactive medications. These included chlorpromazine, flupenthixol, clozapine, sulpiride, clopixol, trifluoperazine, amitriptyline, fluoxetine, lithium, and carbamazepine. Two of the four patients with personality disorders had also received APD medication. As expected, glycaemic control was variable, but on average did not deteriorate during the study. Similarly, BMI remained stable, with mean levels in the range indicating grade $l$ obesity. Interventions by the diabetologist during the study period included the introduction of oral hypoglycaemic agents (OHAs) $(n=3)$, change of OHA doses $(n=4)$, introduction of insulin $(n=5)$, and addition of metformin to insulin

Table 1 Characteristics of, and glycaemic control and complications in, 22 diabetic patients in a high secure hospital. Data are mean (SD), with the range in square brackets

\begin{tabular}{|c|c|}
\hline \multicolumn{2}{|l|}{ Characteristics of patients } \\
\hline Number of subjects & 22 \\
\hline Number with mental illness & 18 \\
\hline $\begin{array}{l}\text { Number with a personality } \\
\text { disorder }\end{array}$ & 4 \\
\hline Age (years) & 45 (12) [27-67] \\
\hline Sex & $\begin{array}{l}18(82 \%) \text { male : } 4(18 \%) \\
\text { female }\end{array}$ \\
\hline Duration of diabetes (years) & $5.0(4.6)[0.2-16.0]$ \\
\hline Duration of follow up (years) & $1.6(0.5)[0.3-2.0]$ \\
\hline Initial BMI $\left(\mathrm{kg} / \mathrm{m}^{2}\right)$ & $33.3(8.5)[22.0-60.0]$ \\
\hline Follow up BMI $\left(\mathrm{kg} / \mathrm{m}^{2}\right)$ & $33.2(7.9)[24.0-55.0]$ \\
\hline \multicolumn{2}{|l|}{ Glycaemic control } \\
\hline Initial HbAlc (\%) & $8.5(1.9)[5.5-13.6]$ \\
\hline Follow up HbAlc (\%) & $8.3(1.6)[5.6-12.0]$ \\
\hline \multicolumn{2}{|c|}{ Complications (values are numbers of patients) } \\
\hline Retinopathy & 3 \\
\hline Neuropathy* & 2 \\
\hline Proteinuria & 2 \\
\hline Cerebrovascular disease & 2 \\
\hline Coronary artery disease & 3 \\
\hline Hypertensiont & 8 \\
\hline Hyperlipidaemia & 12 \\
\hline
\end{tabular}

$(n=1)$. By the end of the follow up period, patients were receiving the following treatments: diet alone $(n=1)$, OHAs $(\mathrm{n}=11)$, insulin $(\mathrm{n}=5)$, insulin plus metformin $(\mathrm{n}=4)$, and insulin plus gliclazide $(\mathrm{n}=1)$. During the study, seven patients refused consultations or prescribed medications for short periods of time, but compliance with treatment was usually excellent. Two patients (9\%) died suddenly from cardiovascular disease during the follow up period. Both of these patients smoked more than 20 cigarettes per day and one had renal impairment (creatinine level of $245 \mu \mathrm{mol} / \mathrm{l}$ ).

\section{Prevalence study}

The prevalence study in September 2001 revealed 35 diabetic patients (six of them (17\%) female) in this hospital-all with type 2 diabetes. There were three Afro-Caribbean males, and the rest were white. The total hospital population on that day was 408 patients ( $11 \%$ female), giving a diabetes point prevalence of $8.6 \%$ (95\% confidence interval $5.9 \%$ to $11.3 \%$ ). In females the prevalence was $13.0 \%$ (95\% confidence interval $7.9 \%$ to $18.1 \%$ ), and in males it was $8.0 \%(95 \%$ confidence interval $6.6 \%$ to $9.4 \%$ ). Details of these patients are shown in table 2. Treatment for diabetes was by diet alone $(n=5)$, OHA $(n=20)$, insulin $(n=5)$, insulin plus metformin $(n=4)$, or insulin plus gliclazide $(n=1)$. Many patients were receiving treatment for other conditions, including chronic obstructive pulmonary disease $(n=12)$, cardiac failure $(n=4)$, and hypothyroidism $(n=4)$. Over $90 \%$ were current smokers, and all of these smoked at least 20 cigarettes per day. Significant obesity was common (table 2), and in many cases hospital records suggested that considerable weight gain had occurred since admission to hospital.

Table 2 The prevalence of diabetes in a high secure hospital. Details of 35 patients present in September 2001. Data are mean (SD), with the range in square brackets

\begin{tabular}{|c|c|}
\hline \multicolumn{2}{|l|}{ Characteristics of patients } \\
\hline Number of patients & 35 \\
\hline Number with mental illness & 27 \\
\hline $\begin{array}{l}\text { Number with a personality } \\
\text { disorder }\end{array}$ & 8 \\
\hline Age (years) & 48 (12) [range 28-78] \\
\hline Sex & $\begin{array}{l}29(83 \%) \text { male : } 6(17 \%) \\
\text { female }\end{array}$ \\
\hline Duration of diabetes (years) & $4.7(4.4)[0.2-16.0]$ \\
\hline Duration of follow up (years) & $1.6(0.5)[0.3-2.0]$ \\
\hline $\mathrm{BMI}\left(\mathrm{kg} / \mathrm{m}^{2}\right)$ & $31.9(7.3)[19.0-55.0]$ \\
\hline \multicolumn{2}{|l|}{ Clinical characteristics } \\
\hline HbAlc (\%) & $7.9(1.6)[5.6-12.0]$ \\
\hline Cholesterol (mmol/l) & $5.2(1.2)[3.2-8.4]$ \\
\hline $\begin{array}{l}\text { Systolic blood pressure } \\
(\mathrm{mm} \mathrm{Hg})\end{array}$ & $127(16.6)[90-170)$ \\
\hline $\begin{array}{l}\text { Diastolic blood pressure } \\
(\mathrm{mm} \mathrm{Hg})\end{array}$ & $76.6(9.9)[50-102)$ \\
\hline \multicolumn{2}{|l|}{ Obesity* } \\
\hline Class 1 & 11 , of which 3 female \\
\hline Class 2 & 6, of which none female \\
\hline Class 3 & 4 , of which 3 female \\
\hline \multicolumn{2}{|c|}{ Complications (values are numbers of patients) } \\
\hline Retinopathy & 3 \\
\hline Neuropathy† & 2 \\
\hline Proteinuria & 2 \\
\hline Cerebrovascular disease & 2 \\
\hline Coronary artery disease & 6 \\
\hline Hypertension $\ddagger$ & 9 \\
\hline Hyperlipidaemiał & 16 \\
\hline
\end{tabular}




\section{DISCUSSION}

This study found that type 2 diabetes was common in a relatively young population $(90 \%$ of patients were below the age of 60 years). Although the confidence intervals were relatively wide, the prevalence of diabetes was higher than would be expected from the background prevalence of known diabetes, ${ }^{1}$ and so the data highlight diabetes as a major health issue in this patient group. Interestingly, this prevalence is similar to that reported recently in a deprived multiethnic population in inner Manchester. ${ }^{12}$ Previous studies in general hospitals in the UK found inpatient prevalence rates of known diabetes of around $8 \%-9 \%$ in Liverpool ${ }^{13}$ and elsewhere. ${ }^{14}$ However, the diabetic patients in this hospital all had type 2 diabetes, whereas in general hospitals, the community and prison environments in the same geographical region ${ }^{15}{ }^{16}$ there were significant numbers of patients with type 1 diabetes.

Schizophrenia was common in this population. An increased prevalence of diabetes has been reported in institutionalised psychiatric patients. ${ }^{56}$ The environment in psychiatric hospitals probably promotes diabetes through risk factors such as diet, physical inactivity, obesity, and smoking. ${ }^{17}$ Obesity and cigarette smoking were both particularly prevalent in this population, and despite dietary advice many diabetic patients had relatively high intakes of sugar and fat and low levels of physical activity. Data collected by the Schizophrenia Outcomes Research Team support the idea that people with schizophrenia are at increased risk of diabetes because of poor lifestyle and physical health. ${ }^{18}$ It is possible that the origins of diabetes antedate hospitalisation, although hospital lifestyle and the widespread use of APDs may be additional factors. The diabetogenic effect of APDs has attracted interest with the introduction of new agents, ${ }^{7}$ although it has been known for some years that chlorpromazine and haloperidol acutely impair insulin secretion. ${ }^{19} 20$ The Schizophrenia Outcomes Research Trial implicated APDs as a cause of diabetes, but observed that diabetes was prevalent before the widespread use of new APDs. ${ }^{18}$ Of the newer drugs, clozapine and olanzepine have been most consistently associated with the development of diabetes, ${ }^{21}{ }^{22}$ although our data do not allow us to comment on the possible contributions of individual drugs. Weight gain may be a significant mechanism causing diabetes in patients receiving newer APDs, ${ }^{21-23}$ although ketosis and apparent insulin deficiency have also been described. ${ }^{24} 25$

Diabetes and its complications are important issues for long stay psychiatric patients. In this study, specialist multidisciplinary diabetes care led to the identification and appropriate treatment of diabetic complications, despite undeniable obstacles including questionable dietary compliance, physical inactivity, smoking, and obesity. Glycaemic control was variable, and, although most patients did not achieve HbAlc in the range $6.5 \%-7.5 \%$, glycaemic control did not deteriorate over time. Similar glycaemic control through specialist care has been observed previously in a prison environment. ${ }^{15}{ }^{16}$ Although mean blood pressure and cholesterol levels were reasonably controlled, the study highlights the risk of cardiovascular disease as a major issue for many patients and points to a further need to promote the cessation of smoking in this population. Finally, among patients without diabetes on entry to the secure hospital environment, those with risk factors such as obesity are at the highest risk, suggesting a need for awareness of diabetic symptoms and, arguably, annual screening. In secure hospitals and other long stay psychiatric institutions improved dietary choice and opportunities for physical activity would help to reduce the risk of type 2 diabetes. ${ }^{26} 27$

\section{Authors' affiliations}

I A MacFarlane, G V Gill, J Pinkney, Department of Diabetes and Endocrinology, University Hospital Aintree, Liverpool, UK

D Finnegan, Ashworth Hospital, Liverpool, UK

\section{REFERENCES}

1 Ismail AA, Beeching NJ, Gill GV, et al. Capture-recapture adjusted prevalence rates of type 2 diabetes are related to social deprivation. $Q J$ Med 1999;92:707-10

2 Currie CJ, Kraus D, Morgan CL, et al. NHS acute sector expenditure for diabetes. The present, future, and excess in-patient costs of care. Diabet Med 1997; 14:686-93.

3 Kooy FH. Hyperglycaemia in mental disorders. Brain 1919;42:214-88.

4 Lorenz WF. Sugar tolerance in dementia praecox and other mental disorders. Arch Neurol Psychiatry 1922;8:184-96.

5 Mukheriee S, Decina P, Bocola V, et al. Diabetes mellitus in schizophrenic patients. Compr Psychiatry 1996;37:68-73.

6 McKee HA, D'Arcy PF, Wilson PJ. Diabetes and schizophrenia-a preliminary study. J Clin Hosp Pharm 1986;11:297-9.

7 Ackerman S, Nolan $\sqcup$. Bodyweight gain induced by psychotropic drugs. Incidence, mechanisms and management. CNS Drugs 1998;9:135-51.

8 Spoelstra JA, Stolk RP, Klungel JA, et al. Antipsychotic drugs may worsen metabolic control in type 2 diabetes. Diabetologia 2001;44(suppl 1):A60.

9 Taylor PJ. Maximum security hospitals: can we do without them? In: Hawton K, Cowen P, eds. Practical problems in clinical psychiatry. Oxford: Oxford University Press, 1992.

10 The Diabetes Control and Complications Trial Research Group. The effect of intensive treatment of diabetes on the development and progression of longterm complications in insulin-dependent diabetes mellitus. N Engl J Med 1993;329:977-86.

11 WHO Consultation on Obesity. Preventing and managing the global epidemic. Geneva: World Health Organisation, 1997:1-276.

12 Riste L, Khan F, Cruikshank K. High prevalence of type 2 diabetes in all ethnic groups, including Europeans, in a British inner city. Diabetes Care 2001;24:1377-83.

13 Masson EA, MacFarlane IA, Power E, et al. A audit of the management and outcome of hospital inpatients with diabetes-resource planning implications for the diabetes care team. Diabetic Med 1992:9:753-5.

14 Currie CJ, Williams DRR, Peters JR. Patterns of in and outpatient activity for diabetes: a district survey. Diabetic Med 1996;13:273-80.

15 Gill GV, MacFarlane IA. Problems of diabetics in prison. BMJ 1989:298:221-3

16 MacFarlane IA, Gill GV, Masson E, et al. Diabetes in prison; can good diabetic care be achieved? BMJ 1992;304:152-5.

17 Hu FB, Manson JE, Stampfer MJ, et al. Diet, lifestyle, and the risk of type 2 diabetes mellitus in women. N Engl J Med 2001;345:790-7.

18 Dixon L, Weiden P, Delahanty J, et al. Prevalence and correlates of diabetes in national schizophrenic samples. Schizophr Bull 2000;26:903-12.

19 Erle G, Basso M, Federspil G, et al. Effect of chlorpromazine on blood glucose and plasma insulin in man. Eur J Clin Pharmacol 1977;11:15-18.

20 Brambilla F, Guastalla A, Guerrini A, et al. Glucose-insulin metabolism in chronic schizophrenia. Dis Nerv Syst 1976;37:98-103.

21 Henderson DC, Cagliero E, Gray C, et al. Clozapine, diabetes mellitus, weight gain and lipid abnormalities - a five year naturalistic study. Am J Psychiatry 2000;157:975-81.

22 Wirshing DA, Spellberg BJ, Erhart SM, et al. Novel anti-psychotics and new onset diabetes. Biol Psychiatry 1998;44:778-83.

23 Kinon BJ, Basson BR, Gilmore JA, et al. Long term olanzepine treatment: weight change and weight related health factors in schizophrenia. J Clin Psychiatry $2001 ; 62: 92-100$.

24 Rigalleau V, Gatta B, Bonnaud S, et al. Diabetes as a result of atypical antipsychotic drugs - a report of three cases. Diabet Med 2000;17:484-6.

25 Koller E, Schneider B, Bennett K, et al. Clozapine-associated diabetes. Am J Med 2001;11:716-23.

26 Tuomilehto J, Lindstrom J, Eriksson JG, et al. Prevention of type 2 diabetes mellitus by changes in lifestyle among subjects with impaired glucose tolerance. N Engl J Med 2001;344:1390-2.

27 Knowler WC, Barrett-Connor E, Fowler SE, et al. Reduction in the incidence of type 2 diabetes with lifestyle intervention or metformin. N Engl J Med 2002;346:393-403. 